\title{
The Relationship of Career Mentoring to Early Career Outcomes*
}

\author{
William T. Whitely, Pol Coetsier
}

\author{
William $T$. \\ Whitely \\ College of \\ Business, \\ University of \\ Oklahoma, \\ Norman, U.S.A. \\ Pol Coetsier \\ Laboratory for \\ Applied \\ Psychology. \\ University of \\ Gent, Belgium
}

\begin{abstract}
This study examines the relationship of career mentoring to the promotions, compensation and satisfaction of 148 early career managers and professionals in Belgium. The results support the conclusion that career mentoring is particularly related to early career promotion histories, to general work satisfaction and career satisfaction. Career mentoring was unrelated to total compensation. These results occurred even after controlling for a variety of factors identified by Pfeffer (1977) and Whitely et al. (1991). Several reasons are provided for the relationship between career mentoring and these early career outcomes. The results suggest a number of areas for future career mentoring research.
\end{abstract}

\section{Introduction}

Studies of the early career progress of managers and non-managerial professionals have been frequently based on the principle that career progress in organizations is determined by ability, achievement, and contribution to the organization (Howard and Bray 1988: 54-80). However, researchers have also recognized that managers' and professionals ' career mobility and financial rewards are often, at least partly, allocated on the basis of informal interpersonal processes (Coates and Pellegrin 1957; Pfeffer 1977). This article presents findings from a study which examines mentoring as a determinant of the early career outcomes of managers and professionals who are graduates of three Belgian management schools. Our purpose is to draw attention to the fact that measures of early career progress and well-being, such as current income, rate of advancement, and general satisfaction, may be related to interpersonal processes such as mentoring. An examination of these relationships provides insight into one largely informal interpersonal process by which people in the early part of their careers are sorted out for rewards offered by their employers. These employers allocate important rewards based on many criteria. To the extent that mentoring influences this allocation process, informal mechanisms are identified which affect managers" and professionals' early career progress and well-being in organizations. Since our focus is on the early career consequences of mentoring, it is not our purpose here to explore the many questions concerned with the mentoring process, such as how one is chosen (or chooses) to be mentored. 
With the exception of single organization studies of early managerial potential (e.g. Bray et al. 1974), previous studies of this early career period provide only limited evidence regarding the nature of career processes (Dreher et al. 1985; Harrell 1969; Pfeffer 1977; Weinstein and Srinivasan 1974). The exception to this observation is the study conducted by Whitely et al. (1991). These authors surveyed a large sample of early career business school undergraduates and MBA alumni from three major colleges of business in the U.S. who had been working from 3-5 years following graduation. After controlling for several alternative sources of explanation, they found that mentoring made a significant contribution to the prediction of early career progress. However, the contribution of mentoring to early promotion history only occurred for young managers and professionals who came from higher socio-economic origins.

Two particular research needs stand out as requiring additional investigation in studies of early career outcomes. First, research has typically used salary as the measure of early career outcomes. We know little about other measures of career outcomes, such as rates of advancement or general satisfaction, and the joint effects of career, personal satisfaction, situational and interpersonal influences on these outcomes. Investigation of additional measures of early career outcomes is important in order to develop a more general understanding of this early career period of professionals and managers. The range of dependent variables studied must be expanded to include additional career processes. especially since the determinants of early career outcomes may differ. We include in our study both a measure of income and a measure of the number of promotions, as criteria of early career progress. We also include measures of general work and career satisfaction as indicators of personal well-being during this career period.

Second, additional typically informal interpersonal influences on early career outcomes need investigation. One widely recognized informal interpersonal influence process is mentoring (Kram 1985). While mentoring has been recognized as an important process for fostering career development and progress, it has not received much systematic attention in research on the careers of managers and professionals (Kram 1985; Zey 1984). In particular, not enough attention has been directed to the effects of mentoring on early career outcomes; the focus has mainly been on the process of mentoring. In this study we explicitly examine the relationship between career mentoring and early career outcomes. Another limitation of most prior mentoring research is its tendency to use a retrospective procedure by including samples of middle level to senior managers. These later career samples are asked to recall prior mentoring experiences. The studies often make recommendations regarding the importance of mentoring for managers and professionals who are at the beginning of their careers (Levinson et al. 1978; Roche 1979). Apart from the post hoc fallacy created by such a retrospective procedure, it may seriously inflate population parameters of the average amount of mentor- 
ing received by early career individuals. This retrospective procedure may also seriously under-estimate parameters of the variability of mentoring received by young managers and professionals, and thus upwardly bias the relationship between mentoring and early career progress or well-being. This retrospective procedure may also confound the career outcomes related to social class and career mentoring since higher level managers tend to have higher social class origins (Granick 1962; Poole et al. 1981).

\section{Career Mentoring Relationships With Early Career Outcomes}

Mentoring is a particular kind of interpersonal relationship that can influence career progress and personal well-being. There are two quite distinct conceptual views of the mentoring construct. The classical or primary construct views mentoring as a relatively long-duration, intense developmental relationship in which protégés receive a broad range of career and psycho-social help exclusively from one senior manager (Clawson 1980; Kram 1985; Levinson et al. 1978). In contrast, the career oriented or secondary construct views mentoring as a short-duration, less intense and less inclusive developmental process. It involves multiple relationships that are more specialized in the kinds of developmental functions protégés receive (Phillips-Jones 1982; Zey 1984). Thomas (1986) delineated a continuum of developmental relationships varying according to duration of contact, degree of mutuality, and relationship functions served. Secondary or career mentoring tends to focus on 'external', career progress-oriented functions, such as sponsorship, coaching, protection, and visibility and exposure, rather than on 'inneroriented' psycho-social developmental functions (Kram 1985).

In this study we have focused on the career or secondary mentoring conceptual view. Career-oriented mentoring may come from protégés' immediate bosses, managers in other units, or more senior managers. There are four reasons why we chose to focus on career or secondary mentoring. First, retrospective data collection procedures, such as those used in many previous studies, are particularly likely to measure the classical mentoring construct. Future directed studies, such as the present one, are more likely to measure the secondary construct, for reasons discussed below. Second, career mentoring is probably easier to come by than classical mentoring given the recent pace of organizational changes and individual career transitions occurring in Belgium and throughout Europe. Indeed, Kram (1985) found that classical mentoring had a very low base-rate of occurrence in those U.S. organizations with very stable, well-structured internal labour markets. Third, given their high career mobility, independence and particular needs, people in early career stages are more likely to have several developmental relationships. rather than just one (Kram 1986; Phillips-Jones 1982). Fourth, labour market supply and demand characteristics, such as the unstable growth and 
decline of adjacent age cohorts, international competition, increased pace of technological change, and the downsizing of organizations combine to push mentoring more in the direction of secondary relationships (Alburg and Kimmel 1986: Stewman and Konda 1983). Yet as Berlew and Hall (1966) noted, early career developmental activities can have long-term effects on the career progress of managers and professionals.

Kram (1985) describes career or secondary mentoring as a comprehensive set of roles and associated activities including coaching, protection, providing information to interpret or anticipate actions, and sponsorship or support. As coaches, mentors seek to develop many interpersonal and intellectual skills in a protégé. As protectors, mentors ensure that protégés are not exposed to political forces before they are ready, or before they are well-briefed on the situation and how to deal with difficult people. As sponsors, mentors actively contrive to get their protégés exposure and visibility through assignments that involve working with other influential managers, and by endorsing the protégé for promotion or special challenging, projects and tasks. Kram (1985) and Phillips-Jones (1982) indicate that secondary mentoring typically does not include psycho-social functions such as providing counselling and friendship. While different mentors may specialize in providing one or a limited range of these activities. the total constellation of secondary mentors is thought to provide a wide range of these career functions (Kram 1985; Phillips-Jones 1982). When the specialized contributions of the constellation of secondary mentors is combined, protégés receive a more comprehensive range of developmental activities that varies primarily in the frequency or amount of each activity provided to them.

Career mentoring differs from other concepts in several important ways such as providing a supportive climate or willingness to help. Career mentoring is an emergent concept since it depends on the combined efforts of a number of more senior persons who provide a comprehensive range of developmental activities focused on a particular young person. A supportive climate may be more associated with a particular manager or may be more general and less focused on singling out particular young people for special attention. Career mentoring activities, such as sponsorship or visibility and exposure, entail public identification with a person. and this carries considerable social and political implications in many organizations.

Also, career mentoring is not a process allocated to all young, inexperienced individuals. It involves conscious selection and commitment by both the mentor and the protégé. Indeed, much of the early career development of substantial numbers of young managers and professionals comes from co-workers rather than superiors (Kram and Isabella 1985). Career mentoring may be particularly sought by young people who view higher-level managers as their major reference group. They may seek out opportunities for developmental experiences provided by those managers who strongly influence upward mobility decisions because their own career goals include upward mobility and their major career anchor is to 
increase their managerial competence (Schein 1986). The developmental relationships they nurture may not only equip them with crucial skills. but may facilitate their passage through social boundaries that act as barriers for other young people (Van Maanen and Schein 1979).

\section{Alternative Predictors of Career Progress and Well-Being}

Although our interest is in the influence of mentoring on early career outcomes, we recognize that there are many career influences and have sought to include several influences other than mentoring as control variables. If career mentoring still makes a significant contribution to the prediction of the outcome measures after the statistical controls are entered, it lends confidence to the importance of the process. Research and theory in labour economics, sociology and management has suggested several influences on measures of compensation, rates of advancement and well-being as indicators of early career outcomes (Pfeffer 1977; Stumpf and London 1981). We have organized these influences into four major categories: human capital, job-organizational characteristics, motivational and demographic.

Human Capital Controls. We have included four human capital factors as control variables: (1) the amount of work experience the person had before and after the business training program; (2) the type of business training the person received; (3) whether or not the person's work history subsequent to the terminal educational program was continuous or interrupted and (4) employer changes. This last human capital variable is one kind of personal investment that has been found to relate to career progress (Nicholson and West 1988). Total compensation and promotion progress are indicators of the value that organizations place on a person's human capital. Human capital variables are also inputs into the employment exchange process and can relate to a person's general work and career satisfaction.

Position and Organizational Controls. These controls include the line or staff position of the respondent and the size of the organization. Line and staff positions develop different skills and motives that can affect career progress and well-being (Child and Ellis 1973; Sayles 1964). Larger organizations have a greater ability to pay and more elaborate internal labour markets offering numerous promotion opportunities, than smaller organizations. Structural variables, such as these controls, are also related to general work satisfaction (Berger and Cummings 1979).

Work Involvement Controls. Average hours worked per week may indicate work involvement and the drive to excel in order to obtain early career rewards. Working longer hours also provides more opportunities to receive career mentoring. Mentors and protégés may use the quieter pariods prior to, or following, the normal work day to explore careerrelated concerns. It is possible that career mentoring and work involvement are reciprocally related to each other and to career progress through 
what Hall and Hougaim (1968) call a 'success syndrome'. Career mentoring can increase work involvement, as well as being influenced by it. Career progress can increase the visibility of a person and make him/her the recipient of even more career help from a whole constellation of mentors. Career progress can also lead to even greater involvement behaviour such as working longer hours.

Demographic Control Variables. Sex differences have been observed in measures of compensation. Recent studies have also found sex differences in career progress among middle and senior manager samples (Nicholson and West 1988). Similar sex differences have been found in indicators of well-being such as general work and career satisfaction. We also include the socio-economic origin of the protégé as a control variable since researchers have commonly viewed social stratification variables as having a significant effect on career progression (Roderick and Yarney 1976). The prevailing view seems to be that individuals from high socialclass origins often experience greater career progress. This view would seem to rest, in part, on the consistent observation that high-level managers tend to come from upper social-class origins (Granick 1962; Poole et al. 1981). Socio-economic origin may also relate to measures of well-being. Social comparison processes, such as relative deprivation, would suggest that individuals who come from more favourable social origins, where there is a history of socio-economic success, will be particularly satisfied with their career success.

In summary, the purpose of this study is to address a single hypothesis among a group of early-career Belgian managers and professionals. The hypothesis is:

H1: After controlling for other variables, career mentoring is related to measures of early-career progress and well-being of managers and professionals.

\section{Methods}

\section{Questionnaire Translation Procedure}

The questionnaire used in gathering data for this study was developed through a translating-back translation procedure. The original English version of the questionnaire was developed by Whitely et al. (1991) and was translated into Dutch following liaison between the present senior author and three Flemish colleagues who are fluent in Dutch and English. The Dutch version was then re-translated into English. This procedure was repeated until an equivalent Dutch version of the original English questionnaire was obtained.

\section{Sample and Procedure}

Using alumni records from the Vlerick Management School, Gent and the University of Antwerp MBA program, all graduates from the classes 
of 1980 through 1983 were surveyed. Graduates from the Vlerick School were alumni of either the Post University Management Program (PUB) or the Junior Management Program (JMP). The PUB program is a oneyear concentrated period of business school course work for students whose earlier degree was in some other field of study. It is designed for a group of highly selected students who have limited work experience. The JMP program is intended for lower level professionals and managers, to prepare them for future responsibilities. As such, the students are somewhat older and have more work experience than PUB students. The JMP program involves two years of course work in traditional business topics. The Antwerp MBA program is a two-year course of study in traditional business topics. A similar procedure was used to draw a random sample of third license graduates (similar to a bachelor's degree) from the Economics School at the State University of Gent. These are graduates from 1980-83 who specialized in accounting, finance or marketing during their academic training. Inclusion of this group provides an additional comparison group and also a sample as similar as possible in educational preparation to the sample studied by Whitely et al. (1991). The sample members self-reported the information on all variables included in this study. These sample members are considered potential recipients of career mentoring or protégés. These potential protégés received a questionnaire and a stamped return envelope. To encourage responses, they uere promised feedback of some basic results, including salary information. In addition, several weeks after the initial mail-out a follow-up letter was sent to all sample members. urging them to complete their survey and mail it in. A total of 176 questionnaires were returned, representing a response rate of 59 percent. Although no precise analyses of respondents versus non-respondents was possible, the response rates were somewhat larger for the PUB program Alumni and the Antwerp MBA program.

The analysis sample was restricted to employed individuals who were working on a full-time basis ( $\geqslant 35$ hours per week). We also eliminated those who pursued additional degrees, were self-employed, or employed in a family-owned business, because of the effects these career directions might have on the level of mentoring activity and on the criterion measures. The analysis sample averaged 33 years of age, and 20 percent were women. All analyses were performed on the 148 individuals with complete data on all variables. The analysis sample includes 63 PUB, 22 Antwerp MBA, 27 JMP and 36 license alumni. Data was collected from all respondents from December, 1986 to February, 1987, or approximately five years after graduation.

\section{Criteria}

Number of Promotions. We measured the total number of promotions received since graduation from one of the four preparatory programs. We defined promotions as involving more than one of the following: signifi- 
cant increases in the scope of responsibilities, significant increases in annual salary, changes in the hierarchical level in the employing company, change in offices or office decor, and becoming eligible for bonuses, incentive or stock plans. We provide several different job, monetary and status elements as a portion of our definition of promotions because the particular combination of elements included may differ from employer to employer. Using this definition, all respondents were asked to record the number of promotions received in their careers since the end of their studies.

Our measure of promotions represents a departure, in several ways, from existing measures of this construct, such as that of Bass and Burger (1979). We used the number of promotions, rather than the ratio of the number of organization levels below a respondent to the total number of organization levels, because we thought respondents would not know the total number of organization levels. Further, research indicates that the number of hierarchical levels differs between functional departments (Evans 1975). Second, we did not use age as a denominator, because doing so would result in deceptively low advancement rates for those who received their degree when older, while younger respondents would have deceptively high rates. As mentioned previously, we used years since graduation' as a control variable in the analyses. Finally, Bass and Burger (1979) used organization size as part of their index of rate of advancement, a reasonable procedure given that their measure was structural, or based on organization characteristics. Our study included organization size as another statistical control. Following one or the other procedure is necessary when a sample include respondents from different sized organizations.

Current Total Compensation. This variable measured financial compensation from the employer in all forms, including direct pay, bonuses, commissions, company stock options, profit-sharing, and other forms of financial compensation. Information on the combined sources was requested in seven total compensation ranges denominated in Belgian francs. This procedure was used to solicit compensation information because respondents would be unlikely to provide exact information as they would view such a request as an invasion of privacy. These seven compensation ranges were listed in an increasingly sequential and nonoverlapping order to form a continuous variable. This procedure for measuring compensation is less satisfactory than asking for exact compensation amounts, because it restricts the range in the criterion measure. All persons within each category will be treated as though their compensation was the same.

General Work Satisfaction was measured using the short-form of the Minnesota Satisfaction Questionnaire (MSQ). This form consists of one item from each of the 20 scales of the long-form of the MSQ. The items selected for inclusion are the most pyschometrically sound ones from each of the twenty scales on the longer version. The twenty items measure satisfaction with intrinsic and extrinsic features of the work 
situation. Examples of intrinsic items include activity, independence, variety, and ability utilization. Examples of extrinsic items include pay, advancement, and working conditions. Respondents indicated their degree of satisfaction with each of the twenty items on five-point Likerttype scales. The internal consistency reliability of this scale was quite acceptable (alpha $=.86)$.

Career Satisfaction was measured on a single Likert-type question. Respondents were asked to circle the alternative that best described their feelings about their career from graduation to the present. The five alternatives ranged from (1) very dissatisfied to (5) very satisfied.

\section{Predictors}

The human-capital control variables were operationalized as follows: (1) work experience was the combined years both before and after the degree; (2) employer changes was the number of times the individual changed employers since graduation from the terminal educational program; (3) two educational dummy variables were created: ( $p$ ) coded third license 0 and PUB-MBA 1 and (j) coded PUB-MBA $=0$ and $J M P=1 ;(4)$ continuous work history was coded 1 if there were work interruptions subsequent to the terminal training program, and 2 for a continuous history.

The job and organization control variables were operationalized as follows: a dummy variable was constructed for the line or staff nature of the current position. Line was coded 1 and staff was coded 2. We chose to use line and staff rather than a more precise coding of current position, for conceptual and methodological reasons. Conceptually, the line and staff designation is likely to include some aspects of Schein's (1986) distinction between managerial competence and technical/functional career anchors. In addition, Child and Ellis (1973) found differences in the vertical and horizontal communication patterns of line and staff positions. Line positions had a vertical communication pattern, while staff positions had a horizontal communication pattern. We also used line and staff rather than managerial and professional in order to save on the degrees of freedom and to allow for the use of additional statistical controls. However, we did ask respondents for their job title and whether their job was considered managerial or professional. Professional positions were further divided into technical, finance/accounting, marketing/sales, purchasing, public information, and human resources categories. The sample sizes in several of these professional categories was insufficient to achieve stable estimates with dummy coding, but the agreement between 'line' or 'staff' and 'managerial' or 'professional' designation was very high (82 percent). Organization size was coded into eight categories ranging from (1) 1-50 employees to (8) 50,000 or more employees.

The work involvement control variable was operationalized as follows: (1) average hours worked per week was the estimate provided by the respondent. The demographic characteristic protégé gender was coded 1 
for female and 2 for male. Respondents self-rated their socio-economic origin using the following categories: (1) The under-class was defined as families who relied heavily on public assistance; having living standards below the poverty level and family members without regular employment, and parents with a low level of schooling. (2) The working poor were defined as families with living standards below the mainstream level, but above the poverty level; parents might be low-paid service workers or operatives, with some secondary school. (3) Working-class families had members with moderately skilled operative or lower-level office jobs and incomes slightly above the national average. (4) Mid-level office-professional or top-level skilled labour jobs, education past secondary school, and incomes somewhat above the national average were attributes of middle-class status. (5) Upper-level managers, higher professionals, and owners of medium-sized businesses with university education and incomes nearly twice the national average composed the uppermiddle class. (6) Members of the social elite, with incomes primarily from earned or inherited assets, with university education were considered upper class. We constructed a dummy variable for the analysis, since the measure of socio-economic origin was an ordinal scale. The two highest social classes were recoded 1 , and include 98 respondents. The four remaining social classes were recoded 0 and included 50 respondents.

Career mentoring practices were measured with ten Likert-type statements concerned with the extent to which respondents had experienced particular kinds of activities during their career, to date, since graduation from the last education program (see Appendix). Our instructions asked the respondents to focus on the extent to which they had experienced each activity during their entire early career, rather than only their current experience. The statements were drawn from Kram's (1985) illustrations of coaching, protection, visibility and exposure, and sponsorship practices, and were abridged or modified for the questionnaire. The questions focused on immediate superiors, higher level managers, or managers in units other than the respondent's, who engaged in these mentoring activities. The mentoring items were heavily oriented toward the 'career' aspects of mentoring (Kram 1985). A mentoring scale was constructed by summing the unweighted item scores to obtain a total career mentoring activity score. Coefficient alpha for the ten item scale was .76 .

\section{Analyses}

In performing regression analyses for explaining variance in the dependent variables, we followed a step-wise procedure. The dependent variables were regressed first on the control variables, and then on mentoring. We used this procedure to determine whether mentoring made a unique and statistically significant additional contribution to the explanation of variance in the dependent variables after initially recognizing the 
contribution of the control variables. This procedure is consistent with the research question investigated. In the step-wise procedure, human capital variables were entered into the initial equation followed, in turn, by the position/organization, involvement and demographic control variables. Mentoring, as the variable of theoretical interest, was entered at the final step.

\section{Results}

The means, standard deviations, and zero-order correlations among all variables are shown in Table 1. The sample characteristics found in Table 1 indicate that the respondents tend to be employed more in staff than in line positions $(x=1.35)$. On average, the respondents work in organizations with between 500 and 2500 employees. They report working an average of about 52 hours per week. A high proportion ( 87 percent) have experienced no career interruptions, and on average they have made about one employer change in their careers. They tend to be satisfied with their working lives (mean 3.86 on a scale where 5 is very satisfied). They also indicate that they are satisfied with their careers since graduation (mean $=3.90$ on a scale where 5 is very satisfied). They have received an average of nearly two promotions in their careers. Their average annual total compensation is approximately $1,325,000$ Belgian francs or $\$ 32,000$ U.S. On average, they have received a moderate amount of mentoring ( 27.2 on a scale ranging from 0 to 50 ) in their careers to date.

The matrix also reveals some interesting correlations that have implications for the conclusions discussed later. For example, career satisfaction is correlated with career mentoring $(r=0.24)$, but not with either number of promotions $(r=0.10)$ or total compensation $(r=0.10)$. Further, total compensation is as related to general work satisfaction as is career mentoring ( $r=0.24$ and $r=0.22$, respectively). Number of promotions received is also significantly related to general satisfaction $(r=0.17)$. These interrelations make some further explanation necessary.

We would suggest two explanations that account for the different pattern of correlations for career satisfaction and general satisfaction. First, the measure of general satisfaction includes several items concerned with extrinsic work factors such as pay and advancement. We would find it very surprising if there was not a significant relationship between the promotion and compensation measures, and experienced general satisfaction.

Second, and in contrast, career satisfaction frequently measures more varied intrinsic and longer-term career orientations. particularly when the sample includes large numbers of managerial and non-managerial professional employees. Note that promotions and, to some extent, total compensation measure outcomes are closely associated with vertical mobility in organization hierarchies. However, there are several reasons to believe that many professionals do not measure their career progress 


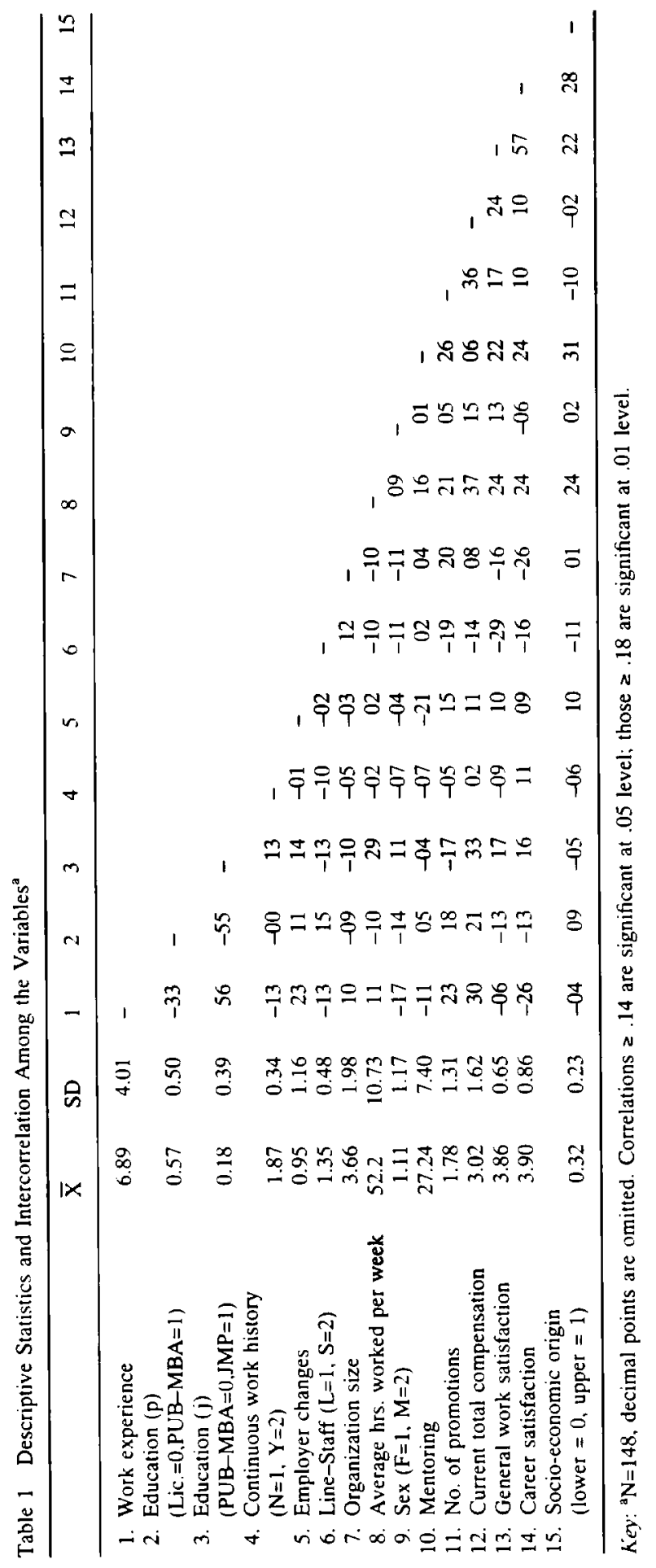


exclusively, or even primarily, using this yardstick. For example, Schein (1986) contrasts technical/functional competence and managerial competence career anchors. The former describes people whose primary orientation is their actual professional work; they prefer to avoid general management positions and prefer personal growth through increasing skill, rather than increasing organization level. The latter describes persons whose primary orientation is to develop managerial abilities and who prefer personal growth through increasing organization level. Research on managerial or line positions shows considerable verbal interaction with superiors (Stewart 1976; Whitely 1985), whereas Child and Ellis (1973) found that professional or staff positions focus more on lateral workflow relationships. Professionals may also evaluate career success in terms of occupational contribution more than in terms of criteria associated with managerial positions (Hunt and Michael 1983; Thompson 1976). Considerations such as these may account for line protégés having greater general satisfaction than staff protégés, but no differences in career satisfaction in the subsequent regression results (see Table 2).

Mentoring was not highly related to any of the control variables except the protégés' socio-economic origin $(r=0.31)$. This indicates that there were no multicollinearity problems nor any potential problems in the interpretation of the regression analysis findings for mentoring. However, there is a significantly negative relationship between number of employer changes and career mentoring. In addition, there is a significantly positive relationship between number of hours worked and career mentoring. Neither of these relationships accounted for more than 5 percent of the variance in career mentoring scores. Only the correlations between the two education dummy variables and between work experience and the education ( $\mathrm{j}$ ) dummy variable indicate some multicollinearity among the control variables.

\section{Prediction of Number of Promotions}

The regression analysis results support the expectation that the amount of mentoring a protégé has received relates to his or her promotion history. Mentoring made a unique contribution to the regression of promotions on the predictors $\left(\mathrm{R}^{2}\right.$ change $\left.=.045 ; \mathrm{F} 1,143=6.82, \mathrm{p}<.01\right)$. In addition to mentoring, two of the human capital variables and both situational control variables contributed to the prediction of number of promotions received by these managers and professionals. Specifically, those with more work experience $(\beta=.22, p<.01)$ and JMP as compared to PUBMBA alumni $(\beta=.26, p<.05)$ had received more promotions. Those in line rather than staff positions $(\beta=-.17, p<.05)$ and who worked in large rather than smaller organizations had received more promotions $(\beta=.17, p<.05)$. Protégés who were more work involved also received more promotions $(\beta=.23, p<.01)$. 


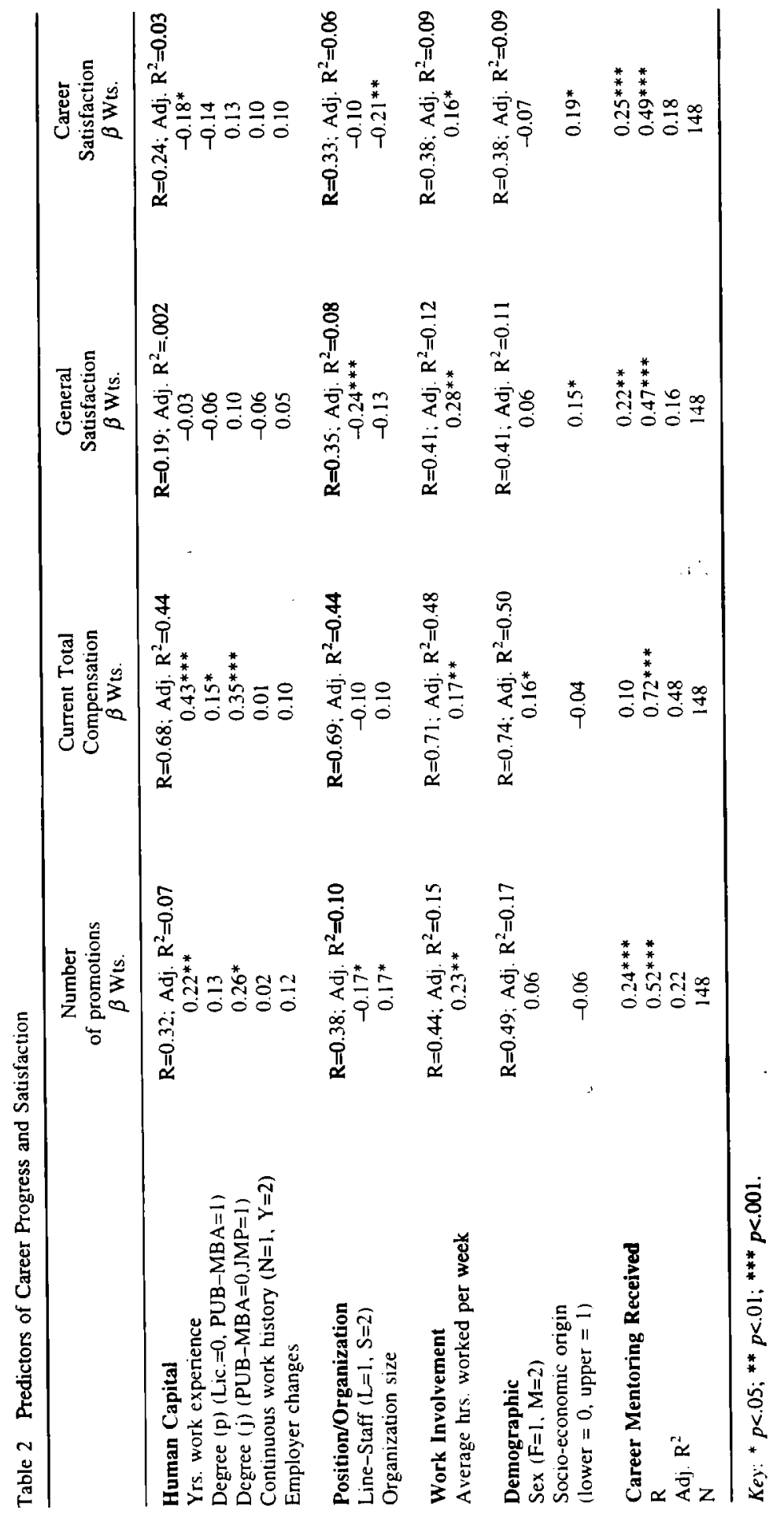




\section{Prediction of Total Compensation}

The regression analysis results in Table 2 for total compensation do not support an interpretation that career mentoring is related to this dependent variable $\left(\mathrm{R}^{2}\right.$ change $\left.=.000 ; \mathrm{F} 1,143=.04, p=.85\right)$. Several of the control variables do predict total current compensation. Specifically, those with greater work experience $(\beta=0.43, p<.01)$. who were graduates of the JMP program $(\beta=.35, p<.001)$ or the PUB-MBA programs $(\beta=.15, p<.05)$; who were more work involved $(\beta=.17, p<.01)$ and male $(\beta=.16, p<.05)$ received higher current total compensation.

\section{Prediction of Work Satisfaction}

The results of the regression analysis shown in Table 2 support the conclusion that career mentoring makes a significant contribution to the prediction of general work satisfaction $\left(\mathrm{R}^{2}\right.$ change $=.044 ; \mathrm{F} 1.143=$ 7.93, $p=.008$ ). Those who have received more mentoring are more satisfied with their general work situation than those who have received less mentoring. In addition, those protégés who are in line rather than staff positions $(\beta$ weight $=-0.24, p<.001)$ and who are more work involved $(\beta$ weight $=.28, p<.01)$ are more satisfied with their work lives. Persons from higher social-class origins also experienced greater work satisfaction $(\beta$ weight $=0.15, \mathrm{p}<.05)$.

\section{Prediction of Career Satisfaction}

The regression analysis results shown in Table 2 support the conclusion that career mentoring makes a significant contribution to the prediction of career satisfaction $\left(\mathrm{R}^{2}\right.$ change $\left.=.068: \mathrm{F} 1.143=9.93, p=.001\right)$. In addition, those with fewer years of work experience $(\beta$ weight $=-0.18$, $p<.05)$, who worked in smaller-sized organizations $(\beta$ weight $=-0.21$, $p<.01)$ and who were more work involved ( $\beta$ weight $=0.16, p<.05)$ were more satisfied with their careers. Persons from higher social-class origins also experienced greater career satisfaction $(\beta$ weight $=0.19, p<.05)$.

\section{Discussion}

Little research has directly addressed the question of the extent to which career mentoring actually contributes to the prediction of early career outcomes. The major contributions of our study are the findings of relationships between career mentoring and both career progress and satisfaction. Our findings partially replicate those found by Whitely et al. (1991). While we did not find a similar relationship between career mentoring and current total compensation, we did find a similar relationship between career mentoring and number of promotions. Also similar to the 
Whitely et al. results is the finding that the socio-economic origin of the protégés is related to the amount of career mentoring they receive. In addition, career mentoring was positively related to both measures of personal well-being.

The most obvious reason for not replicating the relationship between career mentoring and current total compensation is the restriction in variance with the present pay measure as compared to the measure used by Whitely et al. (1991). In the earlier study, exact compensation totals were provided by respondents. For reasons mentioned carlier, we used a categorical reporting scheme in the present study, but categories assume zero variance between individuals within a category, even when there can be significant variations. Such restriction of variance will probably depress correlations and thus understate the true relationship between career mentoring and total compensation.

In the introduction. we explained why we expected to find relationships between career mentoring and both early career success and well-being. We also explained why we expected to find relationships between indicators of social stratification, such as socio-economic origin, and the early career outcome measures. Note that the findings in Table 2 show that socio-economic origin is not directly related to measures of career progress, but is directly related to protégé well-being. Further, compared to individuals from lower-class backgrounds, individuals from higher socio-economic origins report receiving more career mentoring (see Table 1).

There may also be qualitative differences in the mentoring received by respondents from different socio-economic origins, which cannot be detected with the present methodology. Perhaps protégés from higher social-class origins have mentors from higher organization levels, who presumably have more influence and are members of more influential networks than mentors of protégés from lower social-class origins. Since managers tend to have higher social-class origins (Granick 1962; Poole et al. 1981), the social similarity of the mentors and these protégés could strengthen the bond and commitment between them. Protégés from higher social origins are also more likely to share values, skills, and networks with senior managers that may facilitate their passage through social boundaries confronted when being promoted (Van Maanen and Schein 1979). Each of these explanations suggests that. at least to some extent, career mentoring may be particularly beneficial to the early career progress of high social-class protégés.

In conducting this study, we included several control variables that could also relate to the measures of early career progress and well-being. These control variables helped to rule out rival explanations for findings, and strengthened our confidence in the observed relationship between career mentoring and the outcome measures. Indeed, several of the control variables do relate to the outcome measures. Yet, except for current total compensation, career mentoring still makes a significant additional contribution to the prediction of the outcome measures. This significant 
contribution of career mentoring, even after substantial statistical control, is one of the strengths of this study.

Despite the statistical controls, we cannot completely rule out rival explanations, including the post hoc fallacy discussed in the introduction. Our measure of career mentoring asked respondents to focus on their entire early career experience in answering the questions. We don't know the extent to which each promotion may have influenced the subsequent amount or nature of the mentoring a protégé received. That is. promotions may have been a stimulus for mentoring rather than a consequent of mentoring. Discussions with several managers in Europe and the United States suggest this as a plausible explanation for the findings.

There are various reasons why career progress could be both a stimulus for, as well as a consequent of, mentoring. Mentoring is a scarce resource (Kram 1985), because it takes a great deal of time, and the amount of management attention available for devoting to such activities can be quite limited (Mintzberg 1973). Additionally, it may be politically wiser for managers to wait and see who has survived promotion tournaments (Turner 1960; Rosenbaum 1984), before they become identified with a young person as their mentor. For both these reasons. managers may choose to withhold mentoring or certain mentoring activities until a person has gained visibility on their own and has passed through certain social boundaries. Promotions may provide such visibility.

Career mentoring also involves a reciprocal process between the two parties in which the protégé provides the mentor with critical resources (Kram 1985). By supplying these resources a 'coat-tail' effect may operate by which protégés become members of a mentor's coalition (Cyert and March 1963; Weick 1979). As the coalition rises within the organization. the protégé receives additional developmental help from other mentors in his or her coalition. Hence career progress and career mentoring may be reciprocally related in a spiralling 'success syndrome' (Hall and Nougaim 1968).

The present findings also indicate that other factors operate in facilitating career progress and well-being. Protégé work involvement, as measured by the length of the work week, can be important for a protégés preparation for managerial positions, because research has consistently shown that managers work a long week (Cox and Cooper 1989; Mintzberg 1973; Stewart 1976; Whitely 1985). Working longer hours also suggests that more of a protégés interpersonal relationships are work and career focused and may provide greater opportunities for mentoring to occur.

Line managers in the present study report more promotions and greater general satisfaction than staff professionals. Managers have consistently been found to have a greater motivation for vertical mobility than staff professionals (Miner 1965; McClelland and Boyatzis 1982). Managers also have different career anchors than staff professionals (Schein 1986). Those who desire managerial positions may use managers as social referents rather than professional co-workers. They may seek out devel- 
opmental experiences, such as career mentoring, that facilitate vertical mobility and increase personal well-being congruent with their job and career orientations. Managerial positions may also place a greater emphasis on upward, interpersonal relationships than on staff professional positions. Managers may acquire different skills, values and knowledge in vertical exchanges than are acquired in horizontal, workflow-related exchanges characteristic of professional positions (Child and Ellis 1973; Sayles 1964). Acquisition of these personal attributes may further facilitate passage through social boundaries (Van Maanen and Schein 1979) and survival in promotion tournaments (Rosenbaum 1984).

Our measure of mentoring emphasized career functions rather than psycho-social funtions. We focused on career functions because our purpose was to examine the relationship of mentoring on concrete, vertically oriented career success outcomes such as promotions and compensation levels, and on career-oriented measures of well-being. By focusing on career functions, we measured a significant amount of secondary mentoring, which is typically easier to come by than primary mentoring. With secondary mentoring, multiple mentors each provide a limited range of developmental help over the early career span (Kram 1985; Phillips-Jones 1982), thus limiting their time, emotional, social, and political investment in a protégé.

Our research focused on early career mentoring. Our sample is homogeneous in terms of career stage and years since graduation, which is a strength from the standpoint of control in the analysis, but a limitation of our sample is that it does not allow us to generalize the findings to other career stages. For example, career mentoring is likely to play a significant role in vertical success-oriented outcomes at all career stages. However, psycho-social mentoring may particularly benefit individuals from lower socio-economic origins, while being less important for the success of people from higher social origins or those in middle or late career stages. This may be because a mentor's psycho-social efforts may be critical for some protégés' early socialization and self-insight into the relationship between business careers and personal attributes or motivation. Later career protégés may be well-socialized, yet still benefit from career mentoring which will affect their career progress and well-being. Future career mentoring studies should also investigate qualitative differences by gathering information about both the mentor and the protégé on several dimensions. For example, the degree of demographic similarity of superior-subordinate dyads is related to higher ratings of subordinate performance (Turban and Jones 1988). These results support a view that demographic similarity enhances the positive nature of working relationships. The quality and frequency of superior-subordinate interactions relate to subordinate performance (Liden and Graen 1980). These results suggest that we need to more precisely identify components of the career mentoring process which facilitate career progress and personal wellbeing. Information on who the mentors are, especially their level in the 
organization, and their power and influence as indicated by membership in key or dominant coalitions (Cyert and March 1963), may help to improve our understanding of the dynamics of this process. By gathering this information, we could determine if protégés from higher socio-economic origins have more influential mentors than their counterparts with lower social-class origins.

Future studies would also profit from using lengthier measures of career mentoring with separate scales for each of the functions or activities discussed earlier. While past research has shown the separate functions to be highly correlated (e.g. Dreher and Ash 1990), such extended measures may still help to answer additional questions. For example, are there differences in the amount or frequency of particular career mentoring activities between protégés from different social classes. different genders or between those who have experienced different amounts of early career progress? We also recommend longitudinal studies in order to better assess the lagged or reciprocal relationships between measures of early career progress and career mentoring.

The present findings should be considered in terms of their generalizability. The management training programs used as the sources of our sample are located in East Flanders and Antwerp, and share many student and program characteristics. In addition, there are many similarities in the kinds of companies and industries in which the graduates of these programs find employment. These findings may not generalize to business programs with different student composition, or which market their students to a different mix of companies and industries. We should also point out that our respondents self-reported their income category and numbers of promotions. Unfortunately, there is no way to verify this information and investigate the extent to which it may be inflated. but it would require some convoluted explanation to suggest that respondents with more career mentoring were particularly prone to inflate their promotion history and well-being.

Although there are some methodological limitations, these results underscore the importance of further studying the role of career mentoring as a correlate of early career progress and well-being. Career mentoring practices may be an important form of socialization in organizations which relates to indicators of social stratification, and to upward mobility involving the passage through social boundaries within the organization (Van Maanen and Schein 1979). As such mentoring processes may be closely related to general life-span developmental experience (Super 1980). Whatever the explanation, we conclude that career mentoring activity is associated with early career consequences and personal well-being for those young Belgian managers and professionals. With regard to the relationship between career mentoring and promotions, the present results replicate the finding from the Whitely et al. (1991) study of a similar sample of early career U.S. managers and professionals. 
Appendix

\section{Career Mentoring Career Mentoring Scale \\ Function}

visibility and

exposure

My first boss or another boss has been influential in my

exposure

visibility and

exposure

being able to work on assignments with other people out-

side my immediate work area.

coaching

coaching, visibility

and exposure

There is a manager in this organization who has had an influence on what has happened in my career. $\mathrm{S}(\mathrm{he})$ kind of looks out for where I go and what kind of assignments I get.

There is a manager in this organization I have never worked for who has given me an awful lot of confidence in myself. Because $s($ he) has pushed and advised me, I feel that I am growing and am a more valuable person to the company. S(he) has gotten me to do things that I have never enjoyed before (e.g., speaking before groups, speaking before superiors, running a meeting) that now don't bother me.

There is a more senior manager who I do not directly work for who has coached me, or provided me with challenging assignments, or provided me with visibility/ exposure to other managers in the company or pushed and advised me on my career.

coaching

To what extent does your boss or some other superior keep you informed about what is going on at higher levels in the company or how external conditions (industry, government, etc.) are influencing the company?

protection

To what extent has your boss or some other manager protected you from working with other managers or work units before you know their likes/dislikes, who can be trusted/not trusted, relationships between people or the politics of the company?

sponsorship and support

To what extent has your supervisor or some other manager gone out of his/her way to promote your career interests by his/her actions and decisions?

sponsorship and support

How frequently in your career has a direct superior publicly supported or actively nominated you for desirable work assignments which bring you into direct contact with higher level managers?

visibility and exHow frequently in your career have your direct superiors posure, sponsorship given you an assignment that required your personal contact with higher level managers?

visibility and ex- How frequently in your career have your direct superiors posure, sponsorship given you an assignment that required your personal contact with managers in different parts of the company? 
* The data collection, analysis and writing for this study were completed while the first author was on sabbatical and subsequently on a summer research visit at the Laboratory for Applied Psychology, State University of Gent in Belgium. We extend our thanks to Marcel VanLerberge, Dirk DeBruycker and Ann DeWaelle for their assistance at various stages of this study. We would also like to thank Professor Dr. Rita Spoelders-Claes for her help in gathering the data, and for her comments on carlier drafts of this manuscript. In addition, our thanks go to Professor Bill England for his helpful comments on carlier drafts. We would also like to thank Paul Muylle for his help in data analysis. Financial support for this study was reccived from a Noble Summer Research Fellowship, and from the Laboratory for Applied Psychology, State University of Gent. The ideas and opinions expressed herein are solely those of the authors.

\section{References}

Alburg. D., and D. Kimmil

1986 'Human resources management implications of the changing age structure of the U.S. labor force' in Research in personnel and humun resources management, Vol. 4. K. Rowland and G. Ferris (eds.), 339374. Greenwich, C. T.: JAI Press.

Bass. B.. and P. Burger

1979 Assessment of managers: an international comparison. New York: The Free Press.

Berger. C., and L. Cummings

1979 Organization structure, attitudes and behavior' in Research in organizational behavior, Vol. 1. B. Staw (ed.). 169-208. Greenwich. CT: JAI Press.

Berlew, D., and D. Hall

1966 'The socialization of managers: effects of expectations on performance'. Administrative Science Quarterly 2: 2017-223.

Bray, D.. R. Campbell, and D. Grant

1974 Formutive vears in business: a longterm AT\&T study of managerial lives. New York: Wiley.

Child. J.. and T. Ellis

1973 'Predictors of variation in managerial roles". Human Relations 26: $227-250$.

Clawson. J.

1980 'Mentoring in managerial careers' in Work, family and the career. C. B. Derr (ed.). 14-165. New York: Praeger.
Coates, C., and R. Pellegrin

1957 'Executives and supervisors: informal factors in differential bureaucratic promotion'. Administrative Science Quarterly 2: 200-215.

Cox, C., and C. Cooper

1989 'The making of the British CEO: childhood, work experience, personality and management style'. Academy of Management Executive 3: 241-245.

Cyert, R., and J. March

1963 A behuvioral theory of the firm. Englewood Cliffs, N.J.: PrenticeHall.

Dreher. G.. and R. Ash

1990 'A comparative study of mentoring among men and women in managerial, professional and technical positions'. Journul of Applied Psychology 75: 539-546.

Dreher, G., T. Dougherty, and B. Whitely

1985 Generalizability of MBA degree and socio-economic effects on business school graduates' salaries'. Journal of Applied Psychology 70: 769-773.

Evans, $\mathrm{P}$

1975 Multiple hierarchies and organization control'. Administrative Science Quarterly 20: 250-259.

Granick, D.

1962 The European executiv'e. New York: Doubleday.

Harrell. T.

1969 'The personality of high earning MBAs in big business". Personnel Psychology 22: 457-463. 
Hall. D., and K. Nougaim

1968 'An examination of Maslow's need hierarchy in an organization setting'. Organization Behavior and Human Performance 3: 12-35.

Howard, A., and D. Bray

1988 Managerial lives in transition: advancing age and changing times. New York: the Guilford Press.

Hunt, D., and C. Michacl

1983 'Mentorship: a career training and development tool'. Academy of Management Review 8: 475-485.

Kram, K.

1985 Mentoring at work: developmental relationships in organizational life. Glenview. Ill.: Scott Foresman and Company.

Kram, K.

1986 'Mentoring in the work place' in Career development in organizations. D. T. Hall et al. (eds.), 160201. San Francisco: Jossey-Bass.

Kram, K., and L. Isabella

1985 'Mentoring alternatives: the role of peer relationships in career development". Academy of Management Journal 28: 110-132.

Levinson, D., C. Darrow, E. Klein, M. Levinson, and B. McKee

1978 Seasons of a man's life. New York Knopf.

Liden, R., and G. Graen

1980 'Generalizability of the vertical dyad linkage model of leadership'. Academy of Management Journal 23: $451-465$.

McClelland, D., and R. Boyatzis

1982 'Leadership motive pattern and long-term success in management". Journal of Applied Psychology 67: 737-743.

Miner, $\mathbf{J}$.

1965 Studies in management education. New York: Springer.

Mintzberg, $\mathrm{H}$.

1973 The nature of managerial work. New York: Harper and Row.
Nicholson. N., and M. West

1988 Managerial job changes. New York: Cambridge University Press.

Pfeffer, J.

1977 'Toward an examination of stratification in organizations'. Administrative Science Quarterly 22: 553567.

Phillips-Jones, L.

1982 Mentors and protégés. New York: Arbor House.

Poole, M., R. Mansficld, P. Blyton, and P. Frost

1981 Managers in focus: the British manager in the 1980s. Aldershot: Gower.

Roche, G.

1979 'Much ado about mentors'. Harvard Business Review' (January-February): 14-28.

Roderick, R., and J. Yarney

1976 'Developing younger workers: a look at who gets trained'. Journal of Management 2: 19-26.

Rosenbaum, J.

1984 Career mobility in a corporate hierarchy. New York: Academic Press.

Sayles, L.

1964 Managerial behavior. New York: McGraw-Hill.

Schein, E.

1986 'A critical look at current career development theory and research' in Career development in organizations. D. T. Hall et al. (eds.). 310331. San Francisco: Jossey-Bass.

Stewman, S., and S. Konda

1983 Carcers and organizational labor markets: demographic models of organization behavior'. American Journal of Sociology 88: 637-685.

Stewart, R.

1976 Contrasts in management. Maidenhead, England: McGraw-Hill.

Stumpf, S., and M. London

1981 'Management promotions: Individual and organizational factors influencing the decision process: Academy of Management Review 6: 539-549. 
Super. D.

1980 'A life-span, life-space approach to career development'. Journal of Vocational Behavior 16: 282-298.

Thomas, D.

1986 An intra-organizational analysis of black and white patterns of sponsorship and the dynamics of cross-racial mentoring. Unpublished doctoral dissertation. Yale University, New Haven, CT.

Thompson, J.

1976 'Patrons, rabbis, mentors whatever you call them, women need them too'. MBA 10:27, 30. $35-36$.

Turban, D., and A. Jones

1988 'Supervisorsubordinate similarity: types effects, and mechanisms: Journal of Applied Psychology 73: 228-234.

Turner, R.

1960 'Sponsored and contest mobility and the school system'. American Sociological Review 25: 855-867.

Van Maanen. J., and E. Schein

1979 'Toward a theory of organizational socialization in Research in Organizational Behavior. Vol. 1. B. Staw (ed.), 209-264. Greenwich, Conn : JAI Press.
Weick, K.

1979 The social psychology of organizing. Reading, Mass.: Addison-Wesley.

Weinstein. A., and V. Srinivasan

1974 Predicting managerial success of master of business administration (MBA) graduates'. Journal of Applied Psychology 59: 207-212.

Whitely, W. T.

1985 'Managerial work behavior: an integration of results from two major approaches. Academy of Management Journal 28: 344-362.

Whitely, W., T. Dougherty, and G. Dreher

1991 The relationship of mentoring and socio-economic origin to managers' and professionals' early career progress'. Academy of Management Journal 34: 331-351.

Zey. M

1984 The mentor connection. Homewood. Ill.: Dow Jones-Irwin. 